ECCOMAS

Proceedia
COMPDYN 2021

$8^{\text {th }}$ ECCOMAS Thematic Conference on Computational Methods in Structural Dynamics and Earthquake Engineering M. Papadrakakis, M. Fragiadakis (eds.)

\title{
ADVANCES IN COMPUTATIONAL AND ANALYTICAL MODELS FOR COLUMN BASE CONNECTIONS
}

\author{
Pablo Torres-Rodas ${ }^{1}$ \\ ${ }^{1}$ Universidad San Francisco de Quito \\ Diego de Robles \\ e-mail: patorresr@usfq.edu.ec
}

\begin{abstract}
Column Base Connections (CBCs) are one of the most important components of Steel Moment Frames (SMFs) since these connections transfer the loads (e.g., gravity, wind, or earthquake loads) from the superstructure to the foundation. Because of it, CBCs have been extensively studied over the last decade through large-scale experimental programs and computational models that have led to the development of well-developed design guides such as the Design Guide 1 (DG1). Early analytical models were developed to predict the strength of CBCs, while subsequent studies estimated their rotational Stiffness, as well as deformation capacity. Modern studies on the topic have been developed to explore their behavior further with sophisticated finite element simulations. Moreover, their high deformation capacity with desirable hysteretic properties has called the researcher's attention to incorporate CBCs as part of the energy dissipation system.

The broad research conducted on this area points to the importance of CBCs. Motivated by this issue, this paper summarizes the (state of the art) analytical and numerical models that characterize the behavior of CBCs. First, the different types of CBCs used in the industry are described. Next, the analytical models to predict their strength, rotational Stiffness, and hysteretic properties are summarized. Strategies for the development of finite element models, as well as results from simulations, are detailed. The influence of column base behavior on the global performance of SMFs (varying in height) is described. Finally, the author's essential results from ongoing research on ductile base plates are discussed, and lines for future investigations are recommended.
\end{abstract}

Keywords: Base Plates, Analytical Models, Numerical Models, Steel Moment Frames 


\section{INTRODUCTION}

Column Base Connections (CBCs) are, perhaps, the most important component of Steel Moment Frames (SMFs). These connections are designed to transfer the loads from the superstructure (Dead, Live, Wind, Earthquake) into the foundation, being an interface between them (i.e., superstructure and foundation). Depending on the loads that are going to be transferred and the type of building (low rise - high rise), CBCs might be classified into two categories: Exposed Base Plates (EBPs) and Embedded Base Connections (EmBCs). The former consists of a base plate welded to a steel column and anchored to the foundation through steel bolts (a grout pad typically levels the foundation), while the latter detail consists of a steel column with a base plate embedded into a concrete foundation. Typically EBPs are used for low to mid-rise buildings, while EmBCs are the norm for taller buildings. Figure 1 shows a schematic representation of both details.
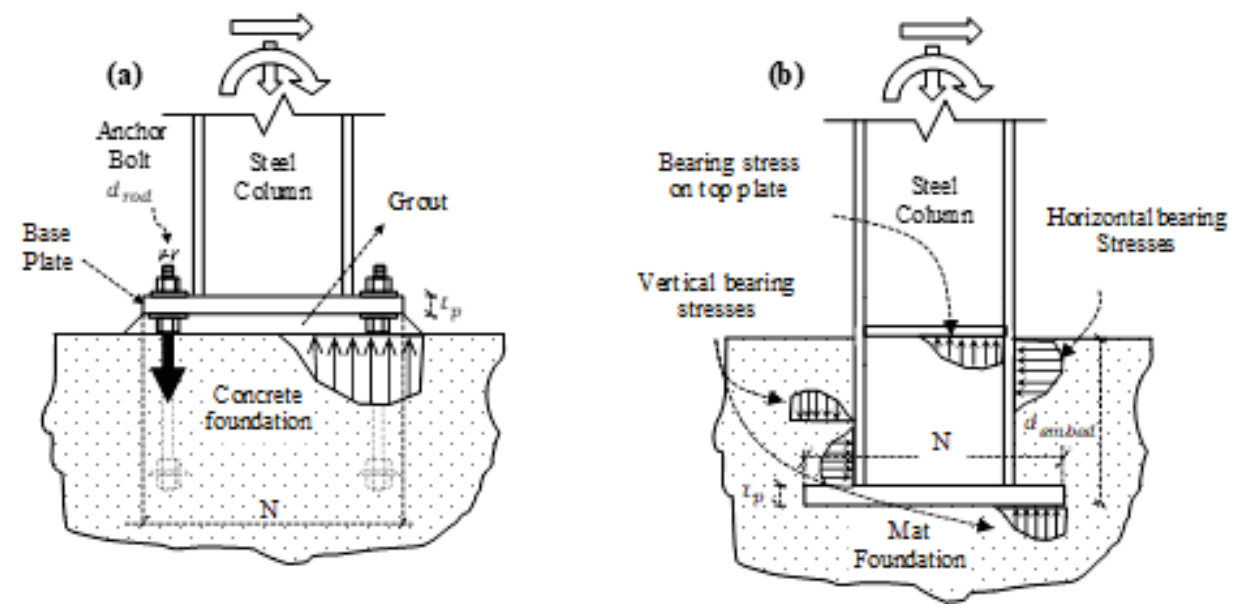

Figure 1: a) EBP detail and the internal force distribution, b) EmBC configuration and the internal force distribution (from Torres-Rodas et al., 2018[12])

The EBPs resist the applied loads by a combination of the bearing stresses developed between the concrete foundation and the base plate and by the tensile forces in the anchor rods. Thus, the axially compressive force is resisted by the bearing stresses in the base plate's compression side, while the Moment is resisted by the couple formed by the resultant compressive force and the tensile force from the bolts (Figure 1a). The shear forces are carried by either friction forces developed between the base plate and the grout/foundation or with a shear key. These connections strongly rely on the level of axial Load applied, and consequently, the relation Moment/Axial Load significantly affects the connection response. Thus, the response of the connection (i.e., Strength, Rotational Stiffness, and Hysteretic characteristics) is defined by complex interactions between its components. Specifically, these interactions refer to the contact and gapping between the base plate and the foundation (or grout pad), and the contact between the top side of the base plate (tension side) and the bottom side of the nut-washers arrangement.

On the other hand, EmBCs resist the applied forces by the horizontal stresses developed between the column flange and the foundation and the vertical stresses in the interface between the embedded base plate and the concrete foundation (Figure 1b). Joint shear forces accompany the horizontal stresses. In contrast with EBPs, EmBCs are no dependent on the ratio of Moment/Axial Load applied. Instead, the experimental evidence [1] indicates that these 
connections depend on the Moment/Shear Load's ratio. Thus, the response of EmBCs is dictated by the embedded depth as well as the cross-section of the steel column.

During the last years, CBCs have been extensively studied due to their importance. Early studies on EBPs focus on the development of strength methods based on the modes of failure [2-4]. These models have been validated in experimental programs [2] and further improved [5]. Subsequent studies focused on estimations of their rotational Stiffness [6] and investigation of their hysteretic characteristics [7]. Sophisticated Finite Element Models have been developed to explore the internal stress distribution further [8]. These studies ended up in notably guides for the design of EBPs, such as Design Guide 1 (DG1) [9]. Similarly, large-scale experimental tests have been conducted on EmBCs. These experimental programs lead to the development of methods to compute the strength [1], rotational Stiffness [10] and describe with computational models the hysteretic behavior of EmBCs [11]. Moreover, Torres-Rodas et al., 2018 [12] focus the attention on the seismic demands on these connections with recommendations for their design.

Recent studies on SMFs [13-18] have explored the consequences of weakening the strength of $\mathrm{CBCs}$ with the intention to leverage their high deformation capacities and desirable hysteretic properties. These studies show that similar performance (assessed in terms of collapse probability at MCE level) can be achieved in the SMF's behavior if CBCs are sized based on the overstrength seismic load combination rather than with the capacity design criteria. Thus, the idea of protecting the connection with the use of the capacity design criteria may be unnecessary.

Consequently, CBCs play an essential role in the behavior of SMFs. Motivated by this issue, this paper summarizes the main studies (in the author's judgment) about the behavior of both EBPs and EmBCs, describing the state of the art on CBC modeling, and presenting recommendations for new lines of research on the topic. The paper is divided into five sections, beginning with this introductory section, while section two presents models to characterize the Strength, Rotational Stiffness, and Hysteretic behavior of EBPs. Section three details the corresponding models for EmBPs, while section four discusses the findings of the effect of CBC's behavior on the performance of SMFs, finalizing the paper with the Conclusion section.

\section{MODELS FOR EXPOSED BASE PLATES}

\subsection{Strength Method}

The analytical methods that quantify the strength of EBPs may be classified into three categories: 1) models that assume a predefined stress distribution on the compression side of the base plate; 2) models that suppose that base plates are rigid and enforce the compatibility of deformation between the components; and 3) sophisticated models that consider the interaction between the modes of deformation of the components. In the context of U.S. construction practice (and in most of the European countries), the first approach is typically adopted for the design of EBPs. The main reason is due to its simplicity in contrast with the other methods. Elkyn and Drake [19] proposed a method that falls in this first category. This method assumes a predefined (either rectangular or triangular) bearing stress form in the connection's compression side. Thus, the Moment is carried by the force-couple developed by the tensile axial forces in the anchor rods and the resultant compressive force from the bearing stresses. The shear forces are taken by either the friction forces in the interface between the base plate and the grout pad/foundation or by a shear key (Figure 1a). On the other hand, the second approach assumes a rigid base plate 
neglecting the base flexibility. The model proposed by Wald et al., [20] is an example of this category. However, studies such as Gomez et al., [5] and Kanvinde et al., [21] have indicated that this approach leads to inaccurate results (against test data) on the nonconservative side. Finally, the third method applies the principles of mechanics to propose a procedure to construct Moment - Curvature diagrams [22, 23] given the size of the base plate, anchor rods, their material properties, and the level of Axial Load. Although the results are accurate and based on fundamental principles, the procedure is relatively complex to be implemented in a design office.

In the context of US construction, the design of EBPs is carried out based on the recommendations of DG1 [9]. DG1 assumes a rectangular stress block on the compression side of the base connection. Depending on the level of Axial Compressive Force, the applied Moment is resisted by: 1) bearing stresses in the compressive side of the base plate (low-eccentricity condition), or 2) the force-couple developed between the tensile forces in the anchor bolts and the resultant compressive forces from the bearing stresses (high eccentricity condition). The critical eccentricity, which separates both conditions, may be calculated as:

$$
e_{\text {crit }}=\frac{N}{2}-\frac{P}{2 B f_{\max }}
$$

In equation $1, N$, and $B$ are the length and width of the base plate, respectively. $P$ is the Axial Load applied, while $f_{\max }$ is the maximum value assumed for the stress block. In the low-eccentricity condition (i.e., $e \leq e_{\text {crit }}$ ), the only limit state possible is base plate bending in the compressive side, while for the high eccentricity condition (i.e., $e \geq e_{\text {crit }}$ ), three limit states can occur: 1) fracture of the anchor bolts, 2) bending of the base plate in the tension side, 3 ) bending of the base plate in the compressive side. The equilibrium equations $\left(\sum F_{y}=0, \sum M_{z}=0\right)$ are solved to determine the internal forces. For the low-eccentricity case, the unknowns are the magnitude of the bearing stresses $\left(f<f_{\max }\right)$ and the length $(y)$ of the rectangular stress block. On the other hand, for the high eccentricity condition, the unknowns are the tensile forces in the anchor rods $(T)$ and the length $(y)$ of the rectangular stress block. The shear forces in these connections are taken by the friction forces in the interface base plate-grout pad or by a shear key designed for this purpose.

As per DG1, the attainment of one of the before-mentioned limit states represents the capacity of the connection. However, subsequent studies such as Gomez et al., 2010 [5] show that EBPs pose a higher strength capacity. In fact, the maximum capacity is reached once a second component of the connection yields. Thus, the first yield of a component is associated with the called Moment at First Yield of the connection, while the Peak Moment is associated with the formation of a mechanism.

DG1 only deals with the uniaxial bending problem. Hassan et al., 2021 [24] extended the concepts of DG1 to EBPs subjected to biaxial bending with Axial Loads to estimate the internal forces. This procedure implies solving the indeterminacies that take place due to the tensile forces in the anchor rods. The authors suggested a predetermined pattern of the anchor rods' forces based on an assumed Instantaneous Axis of Rotation in conjunction with the rectangular stress block assumption from DG1. An iterative process is required to define the position (inclined) of the Neutral Axis once the equilibrium equations are satisfied. The method was validated against a large set of FE simulations for different base plate configurations. 


\subsection{Rotational Stiffness}

Several researchers have studied the flexibility of EBPs (e.g., [22]). Kanvinde et al. 2012 [25] provide a practical method to estimate these connections' rotational Stiffness by aggregating the deformations within its components. The details of this method (which has been validated by [26] are explained next.

The method leverages the assumptions made by DG1to characterize the internal force distribution (i.e., a rectangular bearing stress block). The next step is to estimate the Moment at the first yield of the connection, which is defined as the Moment corresponding to the first yield of one of the connection components, i.e., the anchor bolts, base plate at the tension side, or base plate at the compression side. Once this quantity is computed, it is compared with the critical Moment (related to $e_{c r t}$ ) to define if the connection is under high or low eccentricity. For the first case (i.e., high eccentricity), the internal forces are used to compute the deformations of the three sources of base flexibility: anchor rods elongation, base plate bending (in the tension and compression side), and the concrete foundation. For the low eccentricity case, the method considers the concrete foundation as the only source of flexibility since the base plate is not expected to uplift (and consequently, the anchor rods will not elongate). In this manner, the deformations of the components have been estimated. Thus, the rotation of the connection can be computed by dividing the total deformation of the components by the base plate length. Finally, the Rotational Stiffness is defined as the ratio between the Moment at the first yield and the base rotation. Figure 2 illustrates this definition.

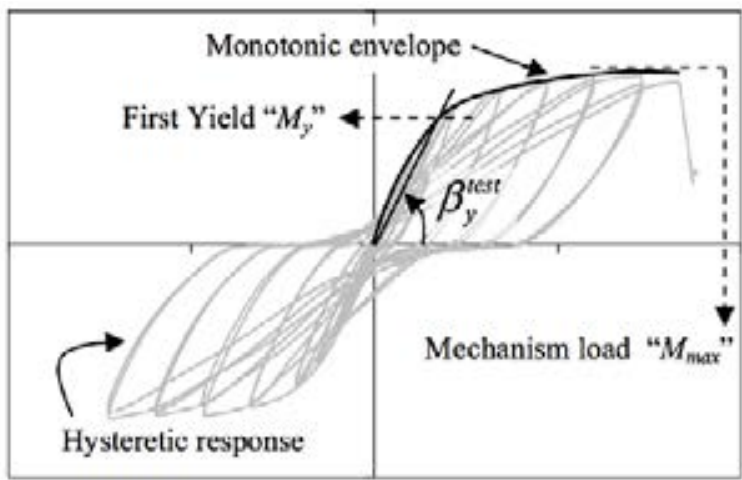

Figure 2: Definition of Rotational Stiffness of EBPs (from [6])

\subsection{Hysteretic Behavior}

The hysteretic characteristics of EBPs have been studied by Torres-Rodas et al., 2016 [7]. These authors proposed a rotational hinge (EBC model) that captures the essential features of the hysteretic behavior of EBPs observed in experimental programs (e.g., [2], [3], [4], [5]). Specifically, this mathematical model consists of a tri-linear backbone curve, a set of hysteretic rules aimed to capture the characteristic shape of the M-Rot curves of EBPs, and rules to capture the modes of deterioration for these connections. Figure 3 illustrates the backbone curve of the model. As per this figure, the backbone curve captures the three initial stages of the connection response. The first stage refers to the linear elastic response. In this phase, the loads are taken by the combination of bearing stresses and tensile forces in the anchor bolts. This phase ends when one of the connection components yields (i.e., base plate or anchor bolts). The element that yielded continues to increase its deformations in the second stage of the response (i.e., strain hardening phase) with an increase in the connection strength. This strength reaches a peak (giving rise to the third phase) when a second component of the connection yields. In this 
manner, a yield plateau is formed in the connection response. Thus, the backbone curve is defined by four parameters: 1) the Moment at First Yield $\left.\left(M_{y}\right), 2\right)$ the Peak Moment $\left.\left(M_{\text {peak }}\right), 3\right)$ the initial Rotational Stiffness $\left(K_{\text {init }}\right)$, and 4$)$ the Rotation associate with the Peak Moment $\left(\theta_{\text {peak }}\right)$. Among these four parameters, the first three of them (i.e., $\left.M_{y}, M_{\text {peak }}, K_{\text {init }}\right)$ can be estimated by the analytical models described in the sub-sections 2.1 and 2.2, while the latter parameter $\left(\theta_{\text {peak }}\right)$ must be obtained experimentally.

In contrast with the monotonic response, the hysteretic rules from the EBC model capture the characteristic flag shape hysteresis and the related re-centering effect. Figure $3 \mathrm{~b}$ shows the details of these hysteretic rules defined by four parameters. These parameters are the Initial Moment at the intermediate plateau, the end position of this intermediate plateau, and two parameters that define the pinching behavior. Only the Initial Moment at the intermediate plateau can be estimated from an analytical model, while the rest of the parameters are obtained by empirical calibrations. The Initial Moment at the intermediate plateau corresponds to the connection moment associate with the instant the anchor bolts start to carry axial forces. Finally, the EBC model captures four modes of cyclic deterioration observed in EBPs. These modes reflect the cycle to cycle decrease in 1) the unloading Stiffness, 2) Peak Strength, 3) Intermediate Plateau, and 4) deformation associated with the intermediate plateau. Four empirically calibrated parameters (two for each mode) are necessary to capture these modes of deterioration. EBC model uses the rule proposed by Rahnama and Krawinkler (1993) [27] to simulate the cyclic deterioration. The assumption of this rule is that deterioration depends on the energy dissipated.
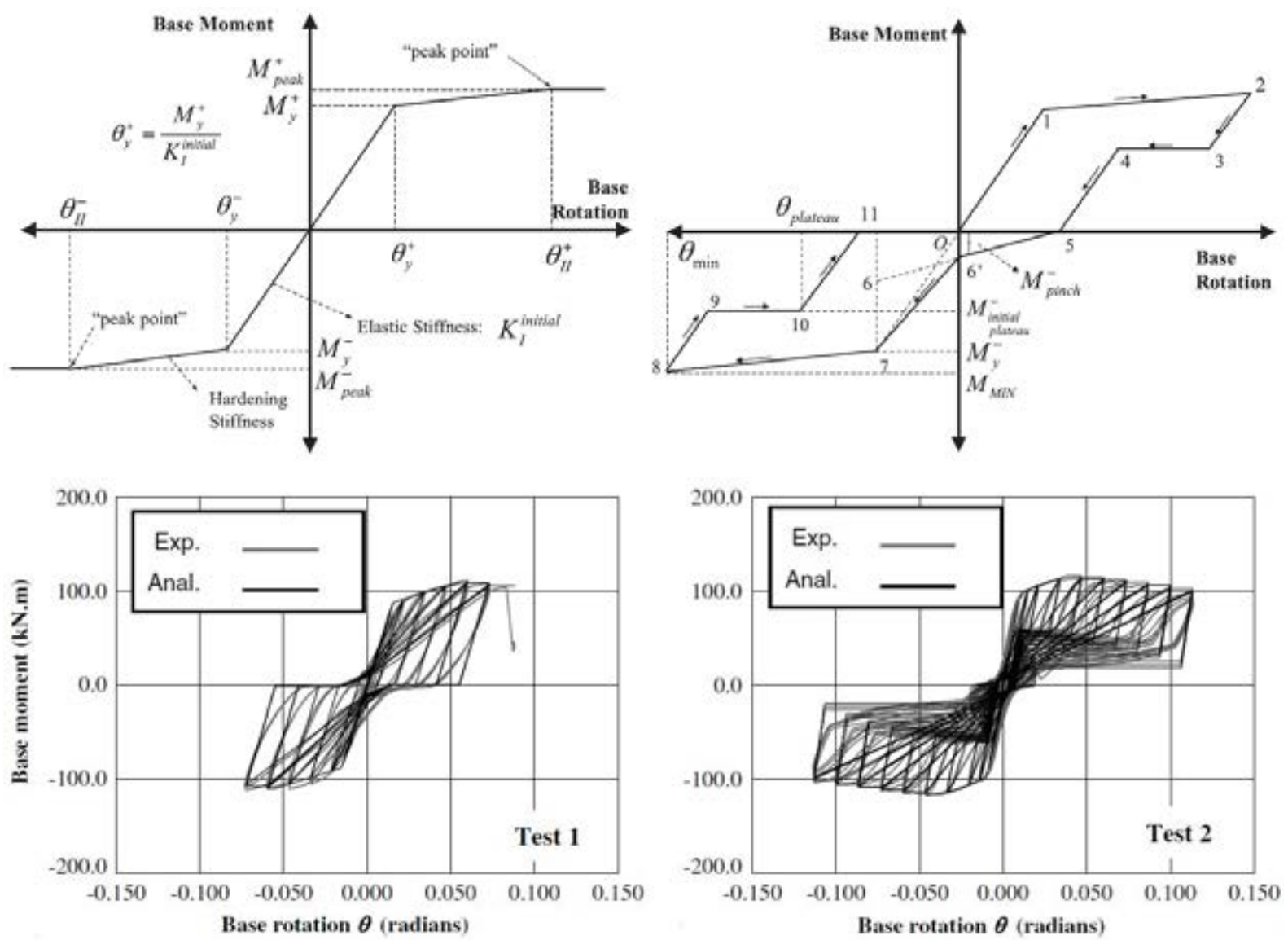

Figure 3: a) Backbone curve of ECB model, b) Hysteretic Rules, c) Calibration Test1, d) Calibration of test 2 (from [7]) 
Figure $3 \mathrm{c}, \mathrm{d}$ shows the validation of the EBC model against the experimental test conducted by [5]. A visual inspection of Figure 3c indicates that the EBC captures the hysteretic response's essential features (i.e., the re-centering effect, the hysteretic shape, and the modes of deterioration). Thus, the EBC model is appropriate to capture the overall connection behavior in Nonlinear Time History (NTH) frame simulations. However, it is important to detail its limitations. First, the EBC model (as all uniaxial plasticity models) cannot capture the Moment-Axial Load interaction. This problem may be treated in an approximate manner, assuming expected values of Axial Load. Second, the model has been validated against a limited number of tests (5 in total). Thus, it is difficult to generalize the EBC model's functionality for connections with significantly different configurations. Finally, the EBC model has not been validated against connections under tensile Axial Load or Biaxial Bending.

\subsection{Finite Element Models}

Several researchers have developed strategies to conduct Finite Element (FE) simulations on EBPs. Krishnamurty and Thambiratnam (1989) [28] presented one of the earliest FE studies conducted on EBPs to validate design methodologies based on the rigid base plate assumption. Stamapolous and Ermopoulos (2011) [29] conducted an experimental and analytical investigation on EBPs developing of 8 tests. These authors constructed 3D FE models to validate the mathematical formulation suggested in [22], and the results indicate a good agreement between the simulations, the experimental results, and the mathematical model suggested. As mentioned before in the paper, one of the drawbacks of this approach is that it is excessively complicated to be implemented in a design office.

Kanvinde et al., 2013 [8] examined the response of EBPs with sophisticated 3D FE simulations. This paper presents critics to the current assumptions regarding the internal stress distributions and suggests. The FE models include essential features of the connection behavior such as contact and gapping between the components (i.e., base plate and foundation/grout pad, nut-washer arrangement, and base plate) and the nonlinear multiaxial constitutive response of the materials. The models were validated against six large-scale tests conducted by Gomez et al., 2010 [5]. Results of this study indicate that the stress distribution in most of the cases is quite different from the assumed rectangular stress block at DG1. Thicker base plates tend to concentrate the stresses in the base plate's toe, while in thinner base plates, the stresses are concentrated under the compression flange of the column. In contrast to the drawbacks found in the internal stress assumption, the simulations indicate that the anchor bolt forces are well estimated by the equations given at DG1.

More recently, Trautner and Hutchinson 2018 [30] presented a procedure for parametric FE simulations of EBPs (with different details) subjected to combined Axial and Moment loads, validating the models against numerous experimental tests. Hassan et al., 2021 [24] studied with FE simulations the behavior (i.e., internal force distribution) of EBPs under combined Axial Compressive Force and Biaxial Bending. These simulations were validated against experimental test data and constituted the basis of the analytical method detailed in sub-section 2.1 for predicting internal forces in EBPs under Biaxial Bending in the presence of Axial Force. Torres-Rodas et al., 2020 [31] developed FE models to study the behavior of EBPs with extended anchor bolts. This configuration detail intends to concentrate all the inelastic action in the extended region of the anchor bolts, protecting the rest of the connection components. 


\subsection{Reliability Analysis of EBPs}

Aviram et al. 2010 [32] carried out a system reliability analysis of the EBPs of a low-rise building located at Berkeley with the intention to evaluate the safety with respect to the different modes of failure reported in the literature. Results of this study indicate that the reliability index for these connections was below the value expected for connections [33]. Torres-Rodas et al., 2020 [34] studied this topic further. These authors evaluated the reliability of EBPs in SMFs designed based on DG1. A statistical approach was suggested to compute strength resistance factors for the modes of failure observed in connections (i.e., concrete bearing, base plate yielding, and anchor bolts failure) [5] to achieve a target reliability index of 4.5. Two buildings were analyzed (2-story and 4-story) using a suite of 120 ground motions from strike-slip and reverse faults. This paper presented a capacity limit state formulation for EBPs considering the M-P interaction, and the focus is on the seismic demands, which are explicitly treated as random variables. Results confirm the reliability index is below the target value. The reliability analysis of EBPs was also studied by Song et al., 2020 [35]. The analysis was conducted using Monte Carlo sampling for the uncertainties from the demands and capacity in this investigation. A total of 59 design scenarios was evaluated. Results confirm the findings from Aviram et al., 2010 and Torres-Rodas et al., 2010 with respect to the reliability index. This study's design recommendation is to eliminate the bearing resistance factor when the flexural demands on the base plate are calculated. Similar to Torres-Rodas et al., 2020, new load resistance factors (with values inferior to the suggested by DG1) are proposed.

\section{MODELS FOR EMBEDDED BASE CONNECTIONS}

\subsection{Strength Method}

Grilli and Kanvinde [1] conducted the first large-scale experimental program on EmBCs for seismic design purposes. The parameters investigated were the embedded length, the column size, and the level of Axial Load. From this experimental program, the modes of failure were identified, and the internal force distribution was postulated. Thus, it is assumed that the Axial Compressive force is resisted by the top stiffener plate as well as the bottom base plate. The applied Moment is resisted through the column flanges at the top of the connection. A fraction of this Moment is resisted by the horizontal stresses against the panel zone, whereas the reminder portion of the Moment is resisted by the vertical bearing stresses at the bottom base plate. The shear forces are resisted by a compression strut formed in the panel zone (Figure 1b).

Once the internal force mechanism is established, the capacities corresponding to each mode of failure can be characterized. Thus, for the horizontal bearing stresses developed in the interface between the column flanges and the concrete foundation, two modes of failure are identified 1) concrete bearing failure and 2) shear failure of the joint panel. On the other hand, the vertical bearing stresses in the bottom base plate entail four modes of failure 1) bearing failure of the concrete surrounding the base plate, 2) concrete breakout under the compression toe of the base plate, 3) concrete breakout above the base plate, and 4) base plate yielding. With these limit states, the Moment capacity associated with the horizontal bearing stresses (i.e., $M_{H B}^{\text {capacity }}$ ) and the Moment capacity associated with the vertical stresses (i.e., $M_{V B}^{\text {capacity }}$ ) might be calculated.

The capacity of the connection is determined by combining $M_{H B}^{\text {capacity }}$ and $M_{V B}^{\text {capacity }}$. These mechanisms are constrained by deformation compatibility, implying that their moment 
contributions are additive (i.e., system in parallel). The fraction of the total Moment to each mechanism is solved by the introduction of an empirical equation that relates the embedded length and the relative Stiffness of the column and the surrounding media. Thus, two scenarios can occur 1) failure due to vertical stresses takes place before failure due to horizontal stresses, 2) failure due to horizontal stresses occurs before failure due to vertical stresses. In the first scenario, the capacity of the connection is dictated by the precise mode of failure within the vertical bearing mechanism. In contrast, if the second scenario occurs, the capacity of the connection depends on which of the two modes of failure controls. If the concrete bearing failure

controls, then $M_{H B}^{\text {capacity }}=M_{H B}^{\text {bearing }}$ and the Moment carried by the horizontal stresses gradually decrease due to an increase in the deformations, and consequently, the vertical stresses will take a larger fraction of the total Moment. If shear failure controls, then no additional moment might be sustained.

\subsection{Rotational Stiffness}

The flexibility of EmBCs has been studied by Tryon 2016 [36] and Torres-Rodas et al., 2017 [10]. Tryon 2016 [36] studied the flexibility of base connections with an overtopping slab, which may be classified as shallowly embedded connections. In this detail, the Moment is carried primarily by the resistance to the uplift of the base plates due to the anchor bolts and by the overlying slab. Usually, the embedded length of these connections is less than $300 \mathrm{~mm}$. In contrast, in deeply embedded base connections, the loads are taken by (as described in the previous subsection) the bearing stresses in the column flanges (i.e., horizontal stresses) and the vertical stresses in the bottom base plate.

Torres-Rodas et al., 2017 [10] presented a method to characterize the rotational Stiffness of EmBcs. This method was developed based on the insights gained from the experimental program conducted by Grilli et al., 2018 [1], and consisted of calculating the components' deformations within the connection (i.e., embedded column and concrete foundation). The method was validated against a total of 9 large-scale tests from the programs conducted by [1] and [36]. The details of the method are explained next.

The method assumes from the experimental tests that the Moment at First Yield occurs at 0.7 of the Peak Moment. The latter parameter is obtained from the strength method earlier described. Thus, the connection stiffness is estimated as the ratio between the Moment at First Yield and the base rotation. Based on the internal force distribution postulated by Grilli and Kanvinde [1], the deformations of the embedded steel column and the surrounding foundation are calculated. Figure $4 \mathrm{a}$ illustrates the patterns of deformations assumed. Finally, the deformations are aggregated to determine the base flexibility (Figure $4 b$ ). 


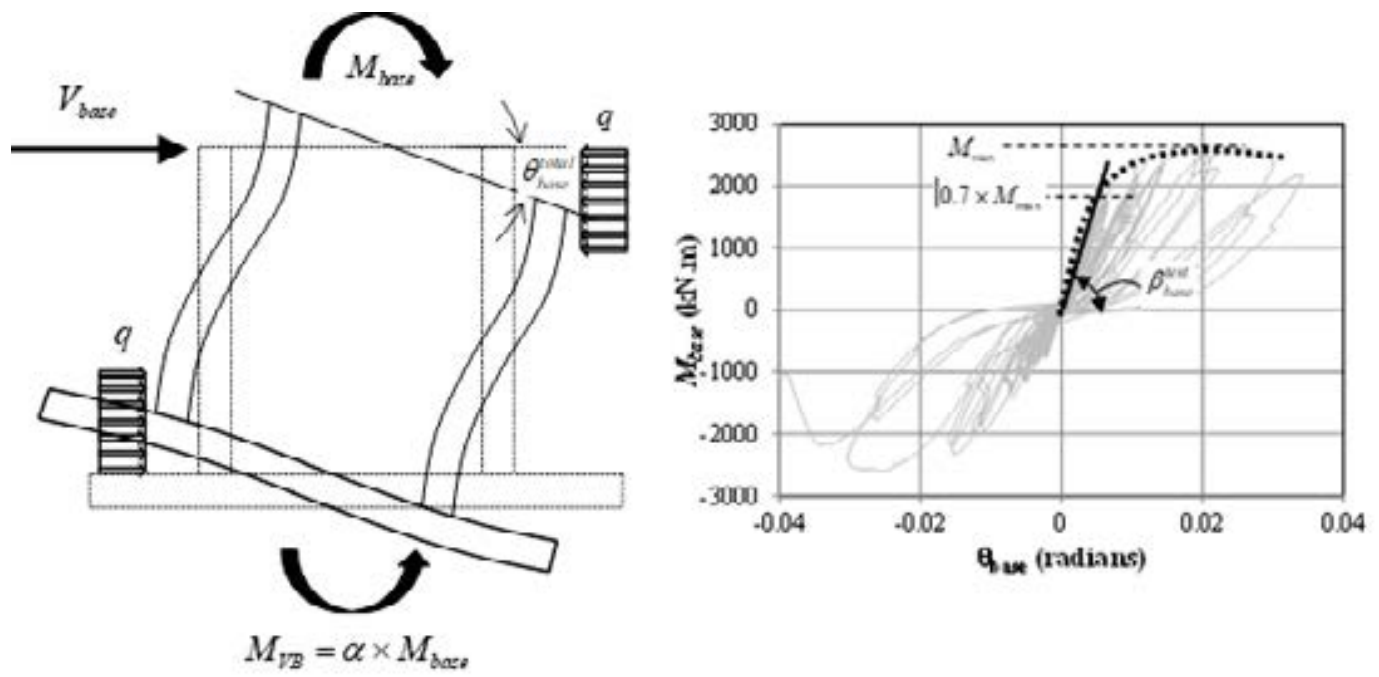

Figure 4: a) Patterns of deformation, b) Definition of Rotational Stifness (from [10])

\subsection{Hysteretic Behavior}

The experimental studies conducted on EmBCs (e.g., [1],[36]) indicate that these connections are ductile with good hysteretic properties. This issue motivated the study by Torres-Rodas et al., 2018 [11] to formulate a mathematical model (EmBC model) to predict the essential characteristics of the behavior of EmBCs for Nonlinear Time History Simulations. The EmBC model is physically based and validated against Grilli and Kanvinde [1]. The details of this model are briefly explained next.

The EmBC model consists of two rotational springs arranged in parallel, where each spring is associated with the force transfer mechanism, i.e., horizontal bearing stress or vertical bearing stress. In this manner, the degradation of the capacity due to horizontal bearing stresses and the corresponding Moment transfer to the vertical bearing stresses is effectively simulated. Thus, the horizontal bearing mechanism is represented by a trilinear backbone curve defined by the well-known Ibarra-Medina-Krawiknler Pinching Model, while the elastic-perfectly plastic model simulates the vertical mechanism. Four parameters (i.e., Initial Elastic Stiffness, Moment at First Yield, Peak Strength, and Rotation Associate with Peak Strength) are necessary to define the spring that represents the horizontal stresses, while two parameters (i.e., Initial Elastic Stiffness, and Moment at First Yield) are required for the vertical bearing spring.

The cyclic response of these connections is described by the IMK Pinching Model's hysteretic rules detailed in Ibarra et al., 2006 [37]. These hysteretic rules capture two important aspects of the cyclic response: 1) pinching behavior, attributed to the closure of cracks or gaps between the column flange and the concrete foundation, 2) cyclic deterioration of two quantities, i.e., the strength plateau and unloading stiffness. The rules proposed by Rahnama and Krawinkler [27] were used to simulate cyclic deterioration and apply only to the horizontal spring since the experimental tests do not provide evidence of deterioration for the vertical spring. Besides, the vertical mechanism gains strength as the horizontal spring deteriorates.

Figure 5, illustrates the results of the validation of the EmBC model against two tests. Clearly, the essential aspects of the connection response are captured by the model formulation and can be easily implemented in NTH simulations. Although the results are promising, the EmBC model has several limitations that must be considered. The model is validated against a limit 
(only five) number of tests. It implies that its results can not be extrapolated to connections with significantly different details. Moreover, it inherits the limitations of a uniaxial plasticity model, i.e., it can not capture the Moment-Axial Load interaction.
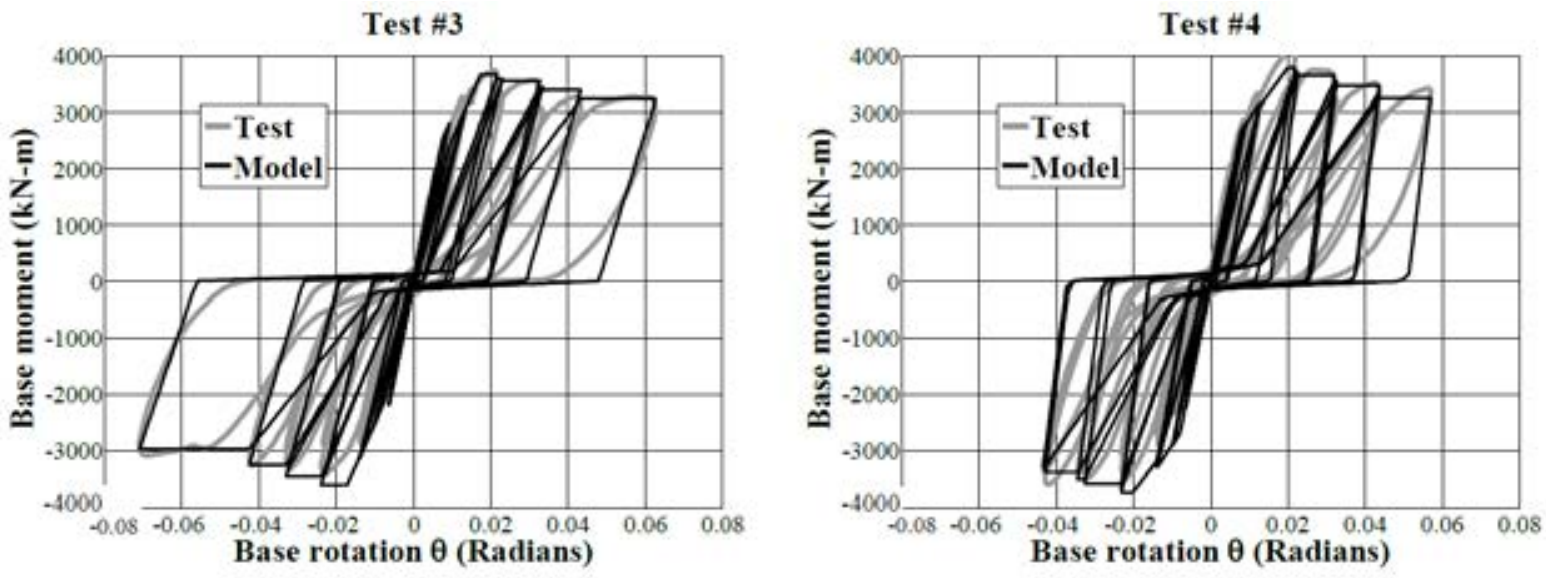

Figure 5: EmBC model validation (from [11])

\subsection{Finite Element Models}

Information about strategies to develop FE models for EmBCs is sparse. Jones 2016 [38] developed 3D FE models for the characterization of the Rotational Stiffness of shallowly embedded base connections. Inamasu et al. [39] studied the seismic design of EmBCs by FE simulations. In this study, the steel column was modeled with shell elements, and the base connection behavior was represented by a rotational spring at the bottom of the column. These models were validated against available tests (e.g., Grilli and Kanvinde [1]). The Finite element models feature the Voce-Chaboche multiaxial plasticity law. The constant parameters were obtained through an optimization process. Local buckling is triggered by considering local imperfections within a certain magnitude. The FE models simulate the response of a design example documented at the AISC Seismic Design Manual. Thus, the connection's response was studied parametrically, being the web local slenderness and the level of Axial Load the parameters investigated. Results indicate that the seismic demands on EmBCs are strongly influenced by the column position (i.e., interior or exterior) and by the cross-section geometry (i.e., local slenderness). Equations empirically calibrated are suggested to promote yielding in the column region above the concrete foundation. More recently, Mora-Bowen and Torres-Rodas [40] further explore the internal force distribution within the components and the patterns of deformation to provide improvements in the design of these connections. This topic is part of the ongoing research projects of the author.

\section{EFFECT OF CBC'S BEHAVIOR ON THE PERFORMANCE OF SMFS}

The effect of CBCs' behavior (i.e., ductility and flexibility) on the seismic response of SMFs has called the attention of researchers during the last years. The main reason is that experimental programs have shown that these connections pose excellent dissipative characteristics with high deformation capacities. Moreover, investigations such as Lignos and Krawinkler 2007 [41] indicate that the ductility of columns in the presence of Axial Compressive Forces might be compromised due to local buckling. Thus, the traditional concept of protecting the connection (remaining elastic) may be unnecessary. This idea may be attributed to the lack of analytical 
models capable of predicting base connections' behavior. However, mathematical formulations such as $[7,11$, and 16] have permitted to capture the overall connection response and incorporate it in NTH frame simulations.

Falborski et al., 2020 [14] studied the effect of Base Connection Strength, Rotational Stiffness, and Deformation Capacity on the Collapse Probability of four archetype frames parametrically. The authors considered four levels of base strength (and the associate Stiffness) and a range of deformation capacities (from 1\% to 5\%) to conduct the collapse assessment. Results indicate that if CBCs are detailed to hold rotations of 0.05rad, the seismic demands in the design can be reduced from the Capacity Design Criteria (1.1RyMp) to the Overstrength Seismic Load $(\Omega=3)$. This is supported by the similar performances (in terms of probability of collapse) achieved by the SMFs analyzed. The implication is that the strength of the connection is decreased by approximately $40 \%$.

Base connections designed to promote anchor bolt yielding have been investigated by Trautner et al., 2016 [26] and Inamasu et al., 2020 [16]. Trautner et al., [26] conducted a series of largescale tests to assess the effect of anchor bolt material type, anchor stretch length, column setting method, and base plate hole size on the behavior of the connection. Among these parameters, the setting method and the stretch length appear to be the most influential in the Moment-Rotation response. Moreover, Inamasu et al., 2020 [16] studied the influence of anchor-yield EBPs in the residual deformations of low-rise SMFs. Results from this study indicate that low-rise buildings with anchor-yield EBPs are less likely to experience residual drifts than buildings with EBPs designed based on the strong connection-weak column criteria. Besides, low-rise buildings with ductile EBPs, do not suffer an axial shortening which may significantly complicate the retrofit work.

More recently, Torres-Rodas et al., 2021 [18] studied the interactive effect of column base hysteretic behavior, continuity of gravity columns, and beam-column gravity connections strength on the seismic performance of SMFs. For each archetype frame, different levels of base connection strength, gravity columns rigidity, and beam-column gravity connections were assigned to assess their impact on the Collapse Probability at MCE level of 5 SMFs varying in height. A total of 80 mathematical models were developed, and NTH simulations were conducted as per FEMAp695 methodology. Results indicate that the presence of continuous gravity columns profoundly affects the archetype frames' behavior investigated by reducing their probability of collapse. In this manner, the desirable hysteretic characteristics of ductile CBCs can be incorporated safely as part of the energy dissipative mechanisms. The design implication is that seismic demands can be reduced (similar conclusion as Falborski et al., 2020) safely to the overstrength seismic loads if base connections can rotate up to $0.05 \mathrm{rad}$.

\section{CONCLUSIONS AND RECOMMENDATIONS FOR FUTURE WORK}

This paper presents a summary (based on the author's judgment) of the numerical and analytical models to characterize the column base connection behavior. Moreover, new findings on the influence of base connection behavior on the seismic performance of SMFs are detailed. The main intention is to synthesize current findings on the topic to highlight the importance of these connections in the overall frame behavior. Thus, the paper is divided into four sections. The first one introduces the topic, while the next two sections describe the main models to simulate 
EBPs and EmBCs. A subsequent section is dedicated to examining the influence of the CBCs on building performance metrics (e.g., collapse probability at MCE level).

Traditionally, CBCs have been sized in order to promote plastic strains in the lower region of the column rather than in the connection itself. This approach may be attributed to 1) the intuitive idea that connections are less ductile than members and 2) the lack of available models to predict the behavior of base connections. However, in the last years, several studies have shown that perhaps this criterion is not appropriate for two main reasons 1) ductility in column members in the presence of Axial Load might be compromised due to local buckling, 2) column base connections pose high deformation capacities with desirable hysteretic properties.

Consequently, several researchers have explored the idea of moving from capacity design criteria to a weak base strong column concept. Results from studies such as [15-18] indicate that reducing the seismic design demands in ductile base connections would lead to similar performance to frames designed with stronger base plates. Moreover, column problems such as axial shortening may be eliminated if plastic strains are concentrated in ductile anchor bolts. This topic has called the attention of researchers and deserves further scrutiny. It is recommended to focus on experimental studies on ductile anchor bolt connections, especially with the intention to facilitate the retrofit work after an earthquake event.

\section{REFERENCES}

[1] Grilli, D.A. and Kanvinde, A.M. (2015). "Embedded Column Based Connections subjected to Flexure and Axial loads," Report 3-11 submitted to the Charles Pankow Foundation.

[2] DeWolf J.T., and Sarisley, E.F. (1980), "Column Base Plates with Axial Loads and Moments," Journal of the Structural Division, ASCE, Vol. 106, No. 11, November 1980, pp. 2167-2184

[3] Astaneh, A., Bergsma, G., and Shen J.H. (1992). "Behavior and Design of Base Plates for Gravity, Wind and Seismic Loads," Proceedings of the National Steel Construction Conference, Las Vegas, Nevada, AISC, Chicago, Illinois.

[4] Burda, J.J., and Itani, A.M. (1999). "Studies of Seismic Behavior of Steel Base Plates," Report No. CCEER 99-7, Reno (NV): Center of Civil Engineers Earthquake Research, Department of Civil and Environmental Engineering, University of Nevada, NV.

[5] Gomez I.R., Kanvinde A.M. and Deierlein G.G. (2010). "Exposed Column Base Connections Subjected to Axial Compression and Flexure," Report Submitted to the American Institute of Steel Construction (AISC), Chicago, IL.

[6] Kanvinde, A.M., Grilli, D.A., and Zareian, F. (2012). "Rotational Stiffness of Exposed Column Base Connections - Experiments and Analytical Models," Journal of Structural Engineering, ASCE, 138(5), 549-560.

[7] Rodas, P. T., Zareian, F., \& Kanvinde, A. (2016). Hysteretic model for exposed column-base connections. Journal of Structural Engineering, 142(12), 04016137.

[8] Kanvinde, A. M., Jordan, S. J., \& Cooke, R. J. (2013). Exposed column base plate connections in moment frames-Simulations and behavioral insights. Journal of Constructional Steel Research, 84, 82-93. 
[9] Fisher, J.M. and Kloiber, L.A. (2006), "Base Plate and Anchor Rod Design," 2nd Ed., Steel Design Guide Series No. 1, American Institute of Steel Construction, Inc., Chicago, IL.

[10] Rodas, P. T., Zareian, F., \& Kanvinde, A. (2017). Rotational stiffness of deeply embedded column-base connections. Journal of structural engineering, 143(8), 04017064.

[11] Torres-Rodas, P., Zareian, F., \& Kanvinde, A. (2018). A hysteretic model for the rotational response of embedded column base connections. Soil Dynamics and Earthquake Engineering, 115, 55-65.

[12] Torres-Rodas, P., Zareian, F., \& Kanvinde, A. (2018). Seismic demands in column base connections of steel moment frames. Earthquake Spectra, 34(3), 1383-1403.

[13] Torres-Rodas, P., Flores, F., \& Zareian, F. (2018). Seismic response of steel moment frame considering gravity system and column base flexibility. In Proc. 11th US Natl. Conf. Earthq. Eng., June 25-29, Los Angeles, USA.

[14] Falborski, T., Torres-Rodas, P., Zareian, F., \& Kanvinde, A. (2020). Effect of baseconnection strength and ductility on the seismic performance of steel moment-resisting frames. Journal of Structural Engineering, 146(5), 04020054.

[15] Torres-Rodas, P., Flores, F., Astudillo, B.X., Pozo, S. (2020). Sensitivity of special steel moment frames to the influence of column-base hysteretic behavior including gravity framing system. Proceedings of the International Conference on Structural Dynamic , EURODYN, 2020, 2, pp. 3629-3642

[16] Inamasu, H., de Castro e Sousa, A., Güell, G., \& Lignos, D. G. (2020). Anchor-yield exposed column bases for minimizing residual deformations in seismic-resistant steel moment frames. Earthquake Engineering \& Structural Dynamics.

[17] Y. Cui, F. Wang, S. Yamada, Effect of Column Base Behavior on Seismic Performance of Multi-Story Steel Moment Resisting Frames, International Journal of Structural $\begin{array}{lllll}\text { Stability } & \text { and } & \text { Dynamics. } & 19 & \text { (2019) }\end{array}$ https://doi.org/10.1142/S0219455419400078.

[18] Torres-Rodas, P., Flores, F., Pozo, S., \& Astudillo, B. X. (2021). Seismic performance of steel moment frames considering the effects of column-base hysteretic behavior and gravity framing system. Soil Dynamics and Earthquake Engineering, 144, 106654.

[19] Drake, R. and Elkin, S. (1999). "Beam-Column Base Plate Design LRFD Method". Engineering Journal.

[20] Wald, F. Column Base Modelling. In Semi-Rigid Joints in Structural Steelwork. Vienna:Springer; 2000, p. 227-288.

[21] Kanvinde A.M., Higgins P., Cooke R.J., Perez J., Higgins J. Column Base Connections for Hollow Steel Sections: Seismic Performance and Strength Models. Journal of Structural Engineering, ASCE 2015; 141(7): 04014171.

[22] Ermopoulos, J. C., \& Stamatopoulos, G. N. (1996). Analytical modelling of columnbase plates under cyclic loading. Journal of constructional steel research, 40(3), 225-238.

[23] Ermopoulos, J. C., \& Stamatopoulos, G. N. (1996). Mathematical modelling of column base plate connections. Journal of constructional steel research, 36(2), 79-100. 
[24] Hassan, A; Torres-Rodas, P; Giulietti, L; Kanvinde, A (2021, in press). Strength characterization of exposed column base plates subjected to axial force and biaxial bending. Engineering Structures.

[25] Kanvinde, A. M., Grilli, D. A., \& Zareian, F. (2012). Rotational stiffness of exposed column base connections: Experiments and analytical models. Journal of structural engineering, 138(5), 549-560.

[26] Trautner, C. A., Hutchinson, T., Grosser, P. R., \& Silva, J. F. (2016). Effects of detailing on the cyclic behavior of steel baseplate connections designed to promote anchor yielding. Journal of Structural Engineering, 142(2), 04015117.

[27] Rahnama, M., and Krawinkler, H. (1993). "Effects of soft soil and hysteresis model on seismic demands" Report No. 108. The John A. Blume Earthquake Engineering Center.

[28] Thambiratnam, D. P., \& Krishnamurthy, N. (1989). Computer analysis of column base plates. Computers \& structures, 33(3), 839-850.

[29] Stamatopoulos, G. N., \& Ermopoulos, J. C. (2011). Experimental and analytical investigation of steel column bases. Journal of constructional steel research, 67(9), 13411357.

[30] Trautner, C. A., \& Hutchinson, T. C. (2018). Parametric finite-element modeling for exposed steel moment frame column baseplate connections subjected to lateral loads. Journal of Structural Engineering, 144(6), 04018049.

[31] Torres, P., Medalla, M., Lopez-Garcia, D., Campos, L., \& Zareian, F. (2021). Strength method for exposed base plates with extended anchor bolts.

[32] Aviram, A., Stojadinovic, B., Der Kiureghian, A. (2010). "Performance and Reliability of Exposed Column Base Plate Connections for Steel Moment-Resisting Frames," PEER Report 2010/107, Pacific Earthquake Engineering Research Center, Berkeley, CA.

[33] Ellingwood, B; Galambos, T; MacGregor, J; Cornell, A. (1980). "Development of a Probabilistic Based Load Criterion for American National Standard A58". National Bureau of Standards.

[34] Torres-Rodas, P., Fayaz, J., Zareian, F. (2020). Strength resistance factors for seismic design of exposed based plate connections in special steel moment resisting frames. Earthquake Spectra, 36(2), 537-553.

[35] Song, B., Galasso, C., \& Kanvinde, A. (2021). Reliability Analysis and Design Considerations for Exposed Column Base Plate Connections Subjected to Flexure and Axial Compression. Journal of Structural Engineering, 147(2), 04020328.

[36] Tryon, J.E., (2016). "Simple models for estimating the rotational stiffness of steel column to footing connections," Masters Thesis, Brigham Young University.

[37] Ibarra, L. F., Medina, R. A., \& Krawinkler, H. (2005). Hysteretic models that incorporate strength and stiffness deterioration. Earthquake engineering \& structural dynamics, 34(12), 1489-1511.

[38] Jones, T. A. (2016). Finite Element Modeling of Shallowly Embedded Connections to Characterize Rotational Stiffness. 
[39] Inamasu, H., Kanvinde, A. M., \& Lignos, D. G. (2021). Seismic design of non-dissipative embedded column base connections. Journal of Constructional Steel Research, 177, 106417.

[40] Mora-Bowen, N., Torres-Rodas, 9. (2021 in press). Nonlinear Finite Element Models for Embedded Base Connections. COMPDYN 2021

[41] Lignos, D. and Krawinkler, H. (2007). "A Database in Support of Modeling of Component Deterioration for Collapse Prediction of Steel Frame Structures”. Structural Engineering Frontiers.

\section{ACKNOWLEDGMENTS}

The author expresses in this paper his profound thanks to his mentors Prof. Farzin Zareian (UC Irvine) and Prof. Amit Kanvinde (UC Davis), for all the lessons learned during and after the doctorate program. The author thanks Universidad San Francisco de Quito for the support given to this publication. 